\title{
A INSERÇÃO FEMININA NO MERCADO DE TRABALHO E SUAS IMPLICAÇÕES NOS HÁBITOS ALIMENTARES DA FAMÍLIA
}

\section{ARTIGO ORIGINAL}

SOUZA, André Luiz Alvarenga De ${ }^{1}$

SOUZA, André Luiz Alvarenga De. A inserção feminina no mercado de trabalho e suas implicações nos hábitos alimentares da família. Revista Científica Multidisciplinar Núcleo do Conhecimento. Ano 04, Ed. 07, Vol. 12, pp. 49-64. Julho de 2019. ISSN: 2448-0959

\section{RESUMO}

Este artigo trata sobre os hábitos alimentares das mulheres inseridas no mercado de trabalho e daquelas que trabalham em casa ditas "do lar". A metodologia utilizada é quantitativa, através de amostragem por conveniência, onde o pesquisador fez a distribuição e recolhimento dos questionários a partir do envio via Google Docs por email e esses e-mails foram selecionados através de uma listagem de correio eletrônico referente aos contatos do próprio pesquisador. O questionário utilizado foi um questionário estruturado, onde as respondentes escolhiam as opções de respostas. A técnica de análise de dados utilizada foi distribuição de frequência e cruzamento de dados. A pesquisa foi realizada na cidade de Campo Grande/ MS, capital de Mato Grosso do Sul, que hoje conta com uma população total estimada de 786.797 habitantes (IBGE, 2010) com uma projeção para 2015 de 853.622 (IBGE, 2015). A questão norteadora ou problemática deste artigo foi discutir o impacto nos hábitos alimentares das famílias decorrentes da inserção da mulher no mercado de trabalho.

Palavras-chave: Hábitos alimentares, mercado de trabalho, mulheres.

${ }^{1}$ Doutorando em Educação, Mestre em Administração, Pós Graduado em Educação a Distância, Pós Graduado em Gestão de Pessoas, Graduação em Administração, Serviço Social, Tecnologia em Gestão de Recursos Humanos, Pedagogia. 


\section{INTRODUÇÃO}

A população feminina vem a cada dia crescendo mais e de acordo com estatísticas do próprio (IBGE, 2010) aponta uma população total feminina de 97.348.809 no Brasil, dados esses que englobam de 0 a 80 anos ou mais e de todas as raças, já a população masculina na mesma faixa etária e raças é de 93.406.990. Isso demonstra a grande demanda feminina para os mais variados tipos de serviços, emprego e renda.

Se fizermos uma análise histórica referente a inserção da mulher no mercado de trabalho, podemos observar que em 1827 surge a primeira lei que permite a mulher frequentar escolas e ter algum tipo de convívio social diferente de seus afazeres domésticos (EDUCAR PARA CRESCER,2009).

O Brasil é um país com fortes carências de registros e informações históricas, mas se formos a fundo podemos observar que a luta da mulher brasileira para seu reconhecimento e posterior entrada no mercado de trabalho vem desde muito antes a Proclamação da República, o que culminou com a elaboração de duas grandes leis, assinadas pela princesa Isabel: (LEI DO VENTRE LIVRE 1871) e (LEI ÁUREA 1888).

A mulher sempre ocupou e ocupara um papel importante na sociedade e nas famílias, Em 1.962, com a entrada em vigor do Estatuto da Mulher Casada, a mulher foi liberada do autoritarismo masculino, o que culminou com sucessivas leis ao seu favor até a promulgação da Constituição Federal de 1.988 a qual reforça a o papel da mulher na sociedade. Homens e mulheres são iguais em direitos e obrigações, (ART $5^{\circ}$ C.F1988).

Neste momento a partir do reconhecimento de seus direitos as mulheres tiveram acesso a inúmeras informações e benefícios ligados a sociedade o que contribui para as várias modificações na estrutura familiar que podemos ver nos dias de hoje. No século XIX ocorreu um movimento referente a revolução cultural feminina o que beneficiou toda a condição das mulheres operárias que aos poucos foram adquirindo direitos e valorização profissional. 
Ao verificarmos este contexto histórico, podemos afirmar que o desaparecimento da sociedade artesanal levou as mulheres a buscarem trabalho nas fabricas e indústrias o que as obrigavam a aceitar salários mais inferiores aos dos homens. Tudo isso resultou na exploração da mão de obra feminina e mazelas da época ligados ao feminismo o que culminou na inserção da mulher na sociedade industrial.

Com a ocupação do pai e da mãe em empregos da indústria, a educação dos filhos ficou em cheque, pois os país (homem) passaram a delegar a educação de seus meninos as mães, mães essas que começaram a trabalhar fora. Já na 1a Guerra Mundial, por envio de seus preceptores aos campos de batalha as mulheres são obrigadas a desempenhar as funções hora exclusiva dos homens e também funções de escritórios, comércios, serviços públicos e até mesmo profissões liberais, o que impulsionou a elevação de seu grau de instrução e consequentemente suas aspirações econômicas e pessoais, passando a exercer outro papel dentro da família.

Com o término da $2^{\underline{a}}$ Guerra Mundial elas veem assegurado na Declaração Universal dos Direitos Humanos, a consagração de seus direitos, sem distinção de sexo, igualando, para todos os efeitos, homens e mulheres.

Conforme estabelece a (DECLARAÇÃO UNIVERSAL DOS DIREITOS HUMANOS 1948, ART 23) :

§1. Toda pessoa tem direito ao trabalho, à livre escolha de emprego, a condições justas e favoráveis de trabalho e à proteção contra o desemprego.

§2. Toda pessoa, sem qualquer distinção, tem direito a igual remuneração por igual trabalho.

§3. Toda pessoa que trabalha tem direito a uma remuneração justa e satisfatória, que the assegure, assim como à sua família, uma existência compatível com a dignidade humana, e a que se acrescentarão, se necessário, outros meios de proteção social. 
Contudo, a inserção feminina no mercado de trabalho é um dos exemplos que pode contribuir para a alteração nos hábitos alimentares da mulher e de sua família, isso porque ainda muitas mulheres são responsáveis, mesmo trabalhando fora, pelo preparo e direção do cardápio de sua família no dia a dia da casa. ( LELIS, TEIXEIRA E SILVA 2013, p. 102), afirmam que, "as mulheres, por tradição, são as principais responsáveis pelas atividades alimentares da família em geral".

Isso também fica claro quando visto pelo prisma de (SILIPRANDI apud. LELIS, TEIXEIRA E SILVA 2013, p. 101), quando afirma que "as mulheres são vistas como um 'instrumento' com o qual se atingirá a segurança alimentar das famílias, ou seja, elas costumam ser guardiãs do bem-estar dos demais membros da família".

(GARCIA 1997) argumenta que a colocação profissional e a independência das mulheres afetam diretamente a estrutura da alimentação e provocam uma organização de valores e hábitos que podem trazer consequências no padrão alimentar familiar.

Deste modo o custo e o tempo dedicado a família e ao preparo do alimento, estão diretamente ligados a demanda de menor tempo de preparação, pois a mulher moderna quer participar mais ativamente da vida de sua família e demonstrar a sociedade um maior comprometimento do ponto de vista afetivo familiar. Isso leva consequentemente a ingestão por parte da família de produtos processados e muitas vezes até fast food.

Para ( BORGES E FILHO 2004), o estudo dos hábitos alimentares é essencial não só no que os consumidores adquirem em termos de alimentos, mas também os fatores que permeiam a escolha destes alimentos.

Outros autores como (RODRIGUES E SABES 2006) e ( SCHLINDWEIN E KASSOUF 2007), destacam que quando as pessoas se alimentam fora de casa, elas intrinsecamente, estão adquirindo valores pessoais em seu cotidiano e que com a inserção da mulher no mundo do trabalho e a falta de tempo para o a escolha do alimento, isso tem afetado na alimentação das famílias e na maneira de preparação 
dos alimentos em seus lares. Isso denota que se alimentar fora de casa com a família deixou de ser algo esporádico para se tornar algo habitual entre as famílias do século $\mathrm{XXI}$.

O que incorre diretamente na saúde da família e também em sua dieta alimentar. Para (LAMBERT, et al 2005), há uma modificação da dieta tradicional para uma dieta na qual as pessoas preferem produtos prontos para

o consumo ou produtos que exijam pouca dedicação durante o seu preparo, como aqueles já cozidos ou pré-cozidos.

Dentro da perspectiva de análise e averiguação da condição feminina no mercado de trabalho, podemos orientar que a pesquisa baseou-se na população feminina que trabalha fora de casa e das mulheres consideradas "do lar" que de alguma forma também trabalham e produzem algo para a sociedade.

A questão norteadora ou problemática deste artigo são os hábitos alimentares das famílias das mulheres que trabalham fora e das que trabalham somente em casa. Objetivo é verificar os hábitos alimentares das famílias com dona de casa que trabalha fora e com dona de casa que não trabalha fora.

\section{METODOLOGIA}

A metodologia utilizada é quantitativa, através de amostragem por conveniência, onde o pesquisador fez a distribuição e recolhimento dos questionários a partir do envio via Google Docs por e-mail e esses e-mails foram selecionados através de uma listagem de correio eletrônico referente aos contatos do próprio pesquisador.

O questionário utilizado foi um questionário estruturado, onde as respondentes escolhiam as opções de respostas, questionário contendo 20 perguntas.

A pesquisa foi realizada na cidade de Campo Grande/ MS, capital de Mato Grosso do Sul, que hoje conta com uma população total estimada de 786.797 habitantes (IBGE, 2010) com uma projeção para 2015 de 853.622 (IBGE, 2015). 
Campo Grande é uma cidade considerada polo agropecuário, com muitas universidades e principalmente voltada a serviços e funcionalismo público, sendo sua economia voltada a estes destaques. O público específico do presente estudo foi constituído por mulheres que trabalhavam nas mais diversas áreas e seguimentos econômicos de Campo Grande/ MS e nas mais variadas profissões e de mulheres consideradas "do lar".

No processo de obtenção dos dados sobre as mulheres optou-se pelos dados do (IBGE, 2010) que aponta uma população feminina de 263.241 na cidade de Campo Grande/ MS, nas idades de 20 á 65 anos ou mais, dentre as quais 126.464 estão economicamente ativas e formalmente (RAIZ/MTE, 2014).

As amostras foram coletadas com total imparcialidade, sigilo e ética e todo este processo de recolha de dados decorreu de 01/10/2015 até 02/12/2015 e resultou num total de 100 questionários enviados e com 40 preenchidos respondidos e validados. No processo de envio dos questionários foi explicado o motivo pelo qual a pesquisa estava sendo realizada e se as mesmas tinham interesse de participar de forma espontânea.

Os dados foram analisados através do perfil socioeconômico das mulheres, sendo observadas e estudadas as variáveis como, idade da entrevistada; estado civil; escolaridade; situação atual de emprego; renda em salários mínimos; número de filhos; número de filhos que moram com elas; se possuem empregada domestica e se a empregada cozinha ou não para elas; quantas refeições costuma fazer diariamente com sua família; com quem costuma realizar as refeições; se considera importante a presença da família durante as refeições; quem é responsável pela compra de alimentos do seu lar; que tipo de alimento é mais comprado, consumido em sua casa; na alimentação fora do lar (self-service, fast food, a la carte), você e sua família, costuma se alimentar com qual frequência; se ela gosta de fazer as refeições fora do seu lar; se ela considera a sua e a alimentação de sua família saudáveis; quanto em média ela costuma gastar com uma refeição do tipo almoço ou jantar quando sai com sua família ou até mesmo sozinha; se ela e a família possui o hábito de comerem na 
mesa; se ela e sua família, durante a semana ou até finais de semana possuem o hábito de comerem de marmitex.

O que buscou identificar e clarificar a luz da pesquisa cientifica as mudanças ocorridas nos hábitos alimentares da família destas pesquisadas com sua inserção no mercado de trabalho e os tipos de alimentos consumidos pelas suas famílias. Foram pesquisados os dois grupos de mulheres que trabalham fora e mulheres que trabalham em casa. Outro detalhe importante levantado também foi se este público gosta de se alimentar fora de sua residência e os valores que estão dispostas a gastar com isso. Também verificado a diferença das refeições de final de semana e durante a semana sua habitualidade.

\section{REFERENCIAL TEÓRICO}

A mulher ocupa hoje em dia diversos papeis na sociedade, mas atualmente existe uma grande diferenciação quando falamos de mulheres inseridas no mundo do trabalho.

Podemos observar que (SOARES E IZAKI 2002), reforça a questão da mulher no mundo do trabalho em sua citação:

Uma das mudanças mais notáveis na oferta de trabalho no pós-guerra tem sido o grande aumento da participação feminina na procura por emprego e ocupação. Embora o fenômeno já fosse incipiente antes da Segunda Guerra Mundial, logo após as mulheres entraram pesadamente no mercado de trabalho. Segundo Goldin (1990), nos Estado Unidos, as mulheres passaram de $18 \%$ da População Economicamente Ativa (PEA) em 1900 para 32\% em 1960 e 46\% em 1992. Foi uma mudança vista em todo o mundo ocidental e o Brasil não escapou aos seus efeitos - no Brasil as mulheres foram de 32\% da PEA em 1977 para 46\% em 2001, fechando em 24 anos o hiato que as mulheres americanas fecharam em 32. Trata-se de um fenômeno de grande importância, pois seu impacto 
foi sentido nas duas instituições mais presentes na vida da maior parte dos indivíduos - a família e o local de trabalho.

Podemos afirmar que o aumento expressivo da mulher no mercado de trabalho é algo que vem de encontro com a mudança da sociedade num todo, novas famílias são constituídas por diversidades o que gera também um grande impacto social e de hábitos.

As mudanças sociais afetam os hábitos alimentares e a exemplo disso podemos destacar o fenômeno da urbanização e demais circunstâncias da modernidade das cidades. As circunstâncias da vida cotidiana têm implicações na relação do indivíduo com o meio em que vive, refletindo-se de tal modo, principalmente no ato de comer e de se relacionar com a alimentação, causando alterações nesses aspectos (MARINHO et al., 2007).

Sabemos que a mulher é a pessoa que decide o que a família irá comer, o cardápio da semana.

Essa mesma mulher trabalha fora e não tem o tempo disponível para fazer essas separações e o preparo desses alimentos, como seria a alimentação das famílias neste caso.

O fato é que a intensificação do aumento populacional, o aumento da urbanização das cidades e a saída da mulher de casa para ao mercado do trabalho modificou a dinâmica das famílias no contexto das relações e também da alimentação. Podemos destacar que conforme (LAMBERT et al. 2005), a falta de regularidade das refeições e seu caráter individual são, também, consequências da modificação no ritmo de vida dos indivíduos.

Isso denota que é necessária uma investigação mais aprofundada no que se refere a inserção feminina no mercado de trabalho e suas implicações nos hábitos alimentares da família. 
De acordo com Lelis, Teixeira e Silva (2013), segundo a pesquisa de orçamentos familiares (POF) realizada pelo IBGE, os brasileiros vêm diversificando sua alimentação, diminuindo o consumo de mercadorias tradicionais e mais básicas, como arroz e feijão. $\mathrm{Na}$ área urbana se destacaram o aumento do consumo de produtos prontos ou processados, como pão de sal, biscoitos recheados, iogurtes, vitaminas, sanduíches, salgados fritos e assados, pizzas, refrigerantes, sucos e cerveja (IBGE, 2011).

Esses dados indicam uma forte demanda da família por comidas prontas, semi prontas e fastfood, o que gera realmente uma mudança na caracterização alimentar das famílias do século XXI.

Quadro 1: Demissões e Variáveis para a análise da inserção feminina no mercado de trabalho e suas implicações nos hábitos alimentares da família.

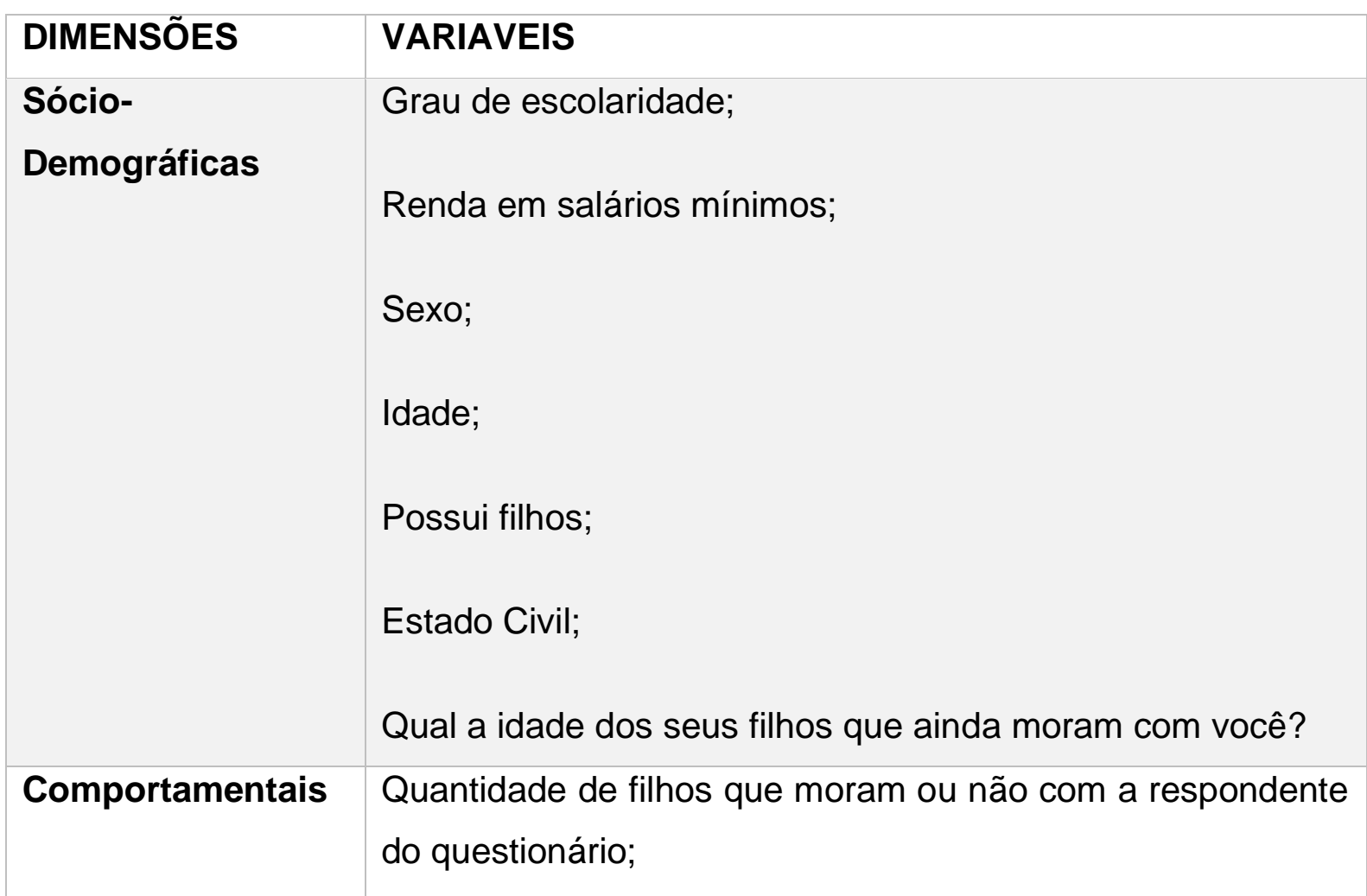


Você possui empregada doméstica? E ela cozinha para você?

Quantas refeições você acostuma fazer diariamente com sua família?

Com quem costuma realizar as refeições?

Você considera importante a presença da família durante as refeições?

Quem é responsável pela compra de alimentos do seu lar?

Que tipo de alimento é mais comprado, consumido em sua casa?

$\mathrm{Na}$ alimentação fora do lar (sel fservice, fast food, a la carte), você e sua família, costuma se alimentar com qual frequência?

Você gosta de fazer as refeições fora de seu lar?

Você considera a sua e a alimentação de sua família saudáveis?

Quanto em média você costuma gastar com uma refeição do tipo almoço ou jantar quando sai com sua família ou até mesmo sozinha?

Você e sua família possui o hábito de comerem na mesa?

Você e sua família, durante a semana ou até finais de semana possuem o hábito de comerem de marmitex?

Fonte: Elaborado pelo próprio autor 
A técnica de análise para tratamento dos dados a qual foi utilizada, refere-se a análise de distribuição de frequência e cruzamento de dados.

\section{DISCUSSÃO E RESULTADOS}

Tabela 1: Cruzamento P7 com P8

\begin{tabular}{|c|c|c|}
\hline Contar de P 8 & P 8 & \\
\hline P 7 & $\begin{array}{l}3 \text { ou mais } \\
\text { refeições }\end{array}$ & $\begin{array}{l}\text { até } 2 \\
\text { refeições }\end{array}$ \\
\hline $\begin{array}{l}\text { Não possuo empregada doméstica e sou eu própria } \\
\text { que cozinho os alimentos da minha família }\end{array}$ & $30,77 \%$ & $69,23 \%$ \\
\hline $\begin{array}{l}\text { Sim possuo empregada doméstica e ela cozinha } \\
\text { para mim. }\end{array}$ & $28,57 \%$ & $71,43 \%$ \\
\hline $\begin{array}{l}\text { Sim possuo empregada doméstica más sou eu } \\
\text { própria que cozinho os alimentos da minha família }\end{array}$ & $0,00 \%$ & $100,00 \%$ \\
\hline
\end{tabular}

Fonte: Elaborado pelo próprio autor

Nesta tabela através dos cruzamentos das variáveis P7 e P8, podemos observar que $100 \%$ das entrevistadas que possuem empregadas domésticas, mesmo as possuindo fazem questão de preparar a comida da família quando a mesma faz até 2 refeições juntos, a partir de 3 refeições ou mais 28,57\% preferem que a empregada doméstica prepare a refeição.

Outro dado considerável a observar é a relação de $69,23 \%$ de mulheres que não possuem emprega doméstica e ela própria cozinha o alimento de sua família. 
Tabela 2: Cruzamento P8 com P9

\begin{tabular}{|l|l|l|l|l|}
\hline Contar de P 9 & P 9 & & \\
\hline P 8 & $\begin{array}{l}\text { Com marido e filhos } \\
\text { (família) }\end{array}$ & $\begin{array}{l}\text { Com } \\
\text { amigos }\end{array}$ & $\begin{array}{l}\text { No } \\
\text { trabalho }\end{array}$ & Sozinha \\
\hline $\begin{array}{l}\text { ou mais } \\
\text { refeições }\end{array}$ & $100,00 \%$ & $0,00 \%$ & $0,00 \%$ & $0,00 \%$ \\
\hline até 2 refeições & $60,00 \%$ & $3,33 \%$ & $3,33 \%$ & $33,33 \%$ \\
\hline
\end{tabular}

Fonte: Elaborado pelo próprio autor

$\mathrm{Na}$ tabela 2, através dos cruzamentos das variáveis $\mathrm{P} 8$ com P9, referentes ao número de refeições e com quem, observamos que até 3 refeições as mulheres fazem com a sua própria família e que até 2 refeições elas fazem com amigos, no trabalho ou até mesmo sozinhas.

Tabela 3: Cruzamento P8 com P12

\begin{tabular}{|l|l|l|}
\hline & P 8 & \\
\hline P 12 & 3 ou mais refeições & até 2 refeições \\
\hline Eu mesma & 3 & 13 \\
\hline Eu mesma, Meu marido & 7 & 17 \\
\hline Total geral & $10 \%$ & $90 \%$ \\
\hline
\end{tabular}

Fonte: Elaborado pelo próprio autor

Através do cruzamento destas variais $\mathrm{P} 8$ e $\mathrm{P} 12$, que se referem ao número de refeições e quem faz as compras para a casa, uma inversão com relação a tabela 2. Aqui constatamos que $90 \%$ responsáveis pelas compras referentes a alimentação do lar são as próprias mulheres e $10 \%$ desse total é compartilhado com os maridos que também fazem as compras domésticas. 
Tabela 4: Cruzamento P8 com P13

\begin{tabular}{|l|l|}
\hline Cruzamento das variáveis P 8 COM P 13 & Porcentagem \\
\hline Alimentos congelados de varias categorias e semi prontos & $33,9 \%$ \\
\hline Legumes, verduras e frutas & $87,5 \%$ \\
\hline Carnes & $51,9 \%$ \\
\hline Enlatados e embutidos (presunto, salsicha, mortadela) & $60,0 \%$ \\
\hline Alimentos orgânicos & $32,5 \%$ \\
\hline
\end{tabular}

Fonte: Elaborado pelo próprio autor

Esta tabela nos traz um dos principais dados referentes ao tipo de consumo de alimentos feitos pelas famílias dessas mulheres pesquisadas, nos mostrando um panorama da alimentação diante uma visão geral das famílias.

Esses dados se dão do cruzamento das variáveis quantidade de refeições feitas diariamente com tipos de alimentos comprados nos supermercados. Diante dos dados detectamos que $87,5 \%$ das pesquisadas consomem legumes, verduras e frutas em seus lares e que diante um hábito considerado saudável um item chamou atenção que é o consumo de enlatados e embutidos do tipo (presunto, salsicha, mortadela) que não são considerados tão saudáveis com percentual de consumo de $60 \%$.

Diante as carnes este público teve um comportamento de consumo referente a 51,9\%, isso significa que o percentual está diretamente ligado ao consumo de proteína animal e que em mais de $50 \%$ dos lares pesquisados está presente na dieta diária das famílias.

No consumo de alimentos congelados de várias categorias e semiprontos temos um percentual de 33,9\% de consumo pelas famílias pesquisadas um índice superior aos dos alimentos orgânicos respondidos pelas pesquisadas que se comportam com percentuais de consumo em $32,5 \%$. 
Tabela 5: Cruzamento de P15 com P17

\begin{tabular}{|l|l|l|}
\hline Contar de P 15 & P 15 & \\
\hline P 17 & Não & Sim \\
\hline De $R \$ 10,00$ até $R \$ 30,00$ & $36,36 \%$ & $63,64 \%$ \\
\hline De $R \$ 101,00$ até $R \$ 300,00$ & $28,57 \%$ & $71,43 \%$ \\
\hline De $R \$ 31,00$ até $R \$ 50,00$ & $30,77 \%$ & $69,23 \%$ \\
\hline De $R \$ 51,00$ até $R \$ 100,00$ & $22,22 \%$ & $77,78 \%$ \\
\hline Total geral & $30,00 \%$ & $70,00 \%$ \\
\hline
\end{tabular}

Fonte: Elaborado pelo próprio autor

Quando tratamos das coisas e as relacionamos a valores, temos a impressão do valor percebido que as pessoas dão ou colocam nas coisas. Diante disso podemos verificar que o percentual de pessoas que preferem comer fora que representa $70 \%$ das pesquisadas é bem maior das que preferem cozinhar e preparar seus próprios alimentos em casa que representam 30\% delas e também não se importam com relação ao aspecto valor financeiro dos alimentos consumidos pela família ou por elas mesmas quando consomem sozinhas em restaurantes, mas existe um percentual de gasto bem expressivo para uma única refeição que corresponde de $R \$ 51,00$

até $R \$ 100,00$ e esta para $77,78 \%$ das entrevistadas que preferem comer fora do lar. Se observarmos as que não gostam de comer fora do seu lar detectamos que essas pesquisadas estão na faixa de consumo de refeições com preço de $R \$ 10,00$ até $R \$$ 30,00 e correspondem a $36,36 \%$ das pesquisadas. 
Tabela 6: Cruzamento de P8 com P14

\begin{tabular}{|c|c|c|c|}
\hline Contar de P 14 & P 14 & & \\
\hline P 8 & $\begin{array}{l}\text { acima de } 5 \text { vezes na } \\
\text { semana }\end{array}$ & $\begin{array}{l}\text { Até } 2 \text { vezes ma } \\
\text { semana }\end{array}$ & $\begin{array}{l}\text { de } 3 \text { a } 5 \text { vezes por } \\
\text { semana }\end{array}$ \\
\hline $\begin{array}{l}3 \text { ou mais } \\
\text { refeições }\end{array}$ & $0,00 \%$ & $80,00 \%$ & $20,00 \%$ \\
\hline até 2 refeições & $3,33 \%$ & $80,00 \%$ & $16,67 \%$ \\
\hline Total geral & $2,50 \%$ & $80,00 \%$ & $17,50 \%$ \\
\hline
\end{tabular}

Fonte: Elaborado pelo próprio autor

Na variável que mede o número de refeições em detrimento ao número de vezes que as pesquisadas costumam comer fora de casa só ou com a família temos as variáveis em número de vezes na semana que nos mostra que $80 \%$ fazem de 2 até 3 refeições na semana fora de casa. No que se refere ao número de 3 a 5 vezes na semana temos $17,50 \%$ que fazem de 2 até 3 refeições fora de casa e acima de 5 vezes na semana temos $3,33 \%$ das pesquisadas que comem fora.

Tabela 7: Cruzamento de P8 com P17

\begin{tabular}{|c|c|c|c|c|}
\hline $\begin{array}{l}\text { Contar de P } \\
17\end{array}$ & P 17 & & & \\
\hline P 8 & $\begin{array}{l}\text { De } R \$ 10,00 \\
\text { até } R \$ 30,00\end{array}$ & $\begin{array}{l}\text { De } R \$ 101,00 \\
\text { até } R \$ 300,00\end{array}$ & $\begin{array}{l}\text { De } R \$ 31,00 \\
\text { até } R \$ 50,00\end{array}$ & $\begin{array}{l}\text { De } R \$ 51,00 \\
\text { até } R \$ 100,00\end{array}$ \\
\hline $\begin{array}{l}3 \text { ou mais } \\
\text { refeições }\end{array}$ & $40,00 \%$ & $40,00 \%$ & $10,00 \%$ & $10,00 \%$ \\
\hline $\begin{array}{ll}\text { até } & 2 \\
\text { refeições } & \end{array}$ & $23,33 \%$ & $10,00 \%$ & $40,00 \%$ & $26,67 \%$ \\
\hline Total geral & $27,50 \%$ & $17,50 \%$ & $32,50 \%$ & $22,50 \%$ \\
\hline
\end{tabular}

Fonte: Elaborado pelo próprio autor 
Esta tabela relaciona-se com a tabela 5, porém aqui temos a quantidade de refeições feitas semanalmente em detrimento ao preço pago pela pesquisa para comer fora de seu lar.

Verificamos que o destaque está para as alimentações que prestigiam os preços de $R \$ 10,00$ até $R \$ 30,00$ e de $R \$ 101,00$ até $R \$ 300,00$ com percentual de $80 \%$ das pesquisadas. Já as que fazem até 2 refeições preferem a precificação de $R \$ 31,00$ até $R \$ 50,00$ e correspondem a $40 \%$ das entrevistadas.

Tabela 8: Cruzamento

\begin{tabular}{|c|c|c|c|c|c|c|c|}
\hline $\begin{array}{l}\text { Contar } \\
\text { de P } 20\end{array}$ & P 20 & & & & & & \\
\hline P 8 & $\begin{array}{l}1^{\circ} \\
\text { Grau }\end{array}$ & $\begin{array}{l}\text { 2o }^{\circ} \\
\text { Grau }\end{array}$ & $\begin{array}{l}\text { Doutora } \\
\text { do }\end{array}$ & $\begin{array}{l}\text { Ensino } \\
\text { Superio } \\
r \\
\text { Comple } \\
\text { to }\end{array}$ & $\begin{array}{l}\text { Ensino } \\
\text { Superior } \\
\text { Incomple } \\
\text { to }\end{array}$ & $\begin{array}{l}\text { Mestra } \\
\text { do }\end{array}$ & $\begin{array}{l}\text { Pós } \\
\text { Graduaç } \\
\text { ão }\end{array}$ \\
\hline $\begin{array}{l}3 \text { ou } \\
\text { mais } \\
\text { refeiçõ } \\
\text { es }\end{array}$ & $0,00 \%$ & $\begin{array}{l}10,00 \\
\%\end{array}$ & $30,00 \%$ & $30,00 \%$ & $10,00 \%$ & $0,00 \%$ & $20,00 \%$ \\
\hline $\begin{array}{l}\text { até } 2 \\
\text { refeiçõ } \\
\text { es }\end{array}$ & $\begin{array}{l}16,67 \\
\%\end{array}$ & $\begin{array}{l}16,67 \\
\%\end{array}$ & $10,00 \%$ & $16,67 \%$ & $6,67 \%$ & $6,67 \%$ & $26,67 \%$ \\
\hline $\begin{array}{l}\text { Total } \\
\text { geral }\end{array}$ & $\begin{array}{l}12,50 \\
\%\end{array}$ & $\begin{array}{l}15,00 \\
\%\end{array}$ & $15,00 \%$ & $20,00 \%$ & $7,50 \%$ & $5,00 \%$ & $25,00 \%$ \\
\hline
\end{tabular}

Fonte: Elaborado pelo próprio autor

Como visto em muitas pesquisas, esta tabela nos denota a importância da escolaridade na vida das pessoas, pois é um fator determinante para saúde dos indivíduos. 
Constata-se nessa pesquisa que quanto maior o nível de escolaridade também é maior o tempo de presença na alimentação com a família, pois entrevistadas que possuem doutorado e pós graduação correspondem a 50\% das entrevistadas que fazem 3 ou mais refeições em casa com a família. Já as pessoas que possuem do $1^{\circ}$ grau até o nível superior completo, passando pelo superior incompleto e mestrado, temos um total de $50 \%$, a observação é válida pois aqui pegamos 3 categorias diferentemente da anterior que mediu apenas 2.

Quando fazemos o comparativo de até 2 refeições com a família, dentro das variáveis $1^{\circ}$ grau, $2^{\circ}$ grau e ensino superior incompleto, verificamos que o valor correspondente é de $40 \%$ das entrevistadas. Com relação as que possuem, nível superior completo, pós graduação, mestrado ou doutorado o nível de 2 refeições com a família sobe para $60,01 \%$.

\section{CONSIDERAÇÕES FINAIS}

Dentro da perspectiva do objeto de estudo deste artigo, que esta diretamente ligada a inserção feminina no mercado de trabalho e suas implicações nos hábitos alimentares da família, este estudo pode concluir que a mulher é fator preponderante na alimentação de sua família, ela é a responsável direta e indiretamente pela saúde de todos da casa, ela trabalhando fora ou somente em casa.

Isso ficou bem claro no estudo diante as variáveis pesquisadas e cruzadas, onde observamos que as mulheres são responsáveis pelas compras nos supermercados e que também gostam muito de saírem para comer fora de suas casas, tendo uma incidência neste hábito de $70 \%$ no total das pesquisadas.

Este estudo também encontrou também um ponto muito importante que são os hábitos alimentares das pesquisadas e de sua família nos mostrando que em $50 \%$ dos lares das pesquisadas o consumo de proteína animal em forma de carne in natura é frequente e $87,5 \%$ das pesquisadas consomem legumes, verduras e frutas em seus lares o que é um hábito considerado saudável. Em $60 \%$ das entrevistadas a alimentação delas e da família também tem doses de enlatados e embutidos do tipo 
(presunto, salsicha, mortadela) que não são considerados tão saudáveis. Outro destaque para o estudo está no consumo de alimentos congelados de várias categorias e semi prontos temos um percentual de 33,9\% de consumo pelas famílias pesquisadas contra $32,5 \%$ dos alimentos orgânicos consumidos pelas respondentes.

Este trabalho apresenta suas limitações de ordem metodológica, que provém do fato de que as pessoas tendem a responder da forma que consideram socialmente correta e neste caso, não relatam especificamente sua realidade (LIMA FILHO 2009). estudo procurou destacar a importância também do grau de instrução das pessoas em detrimento ao número de refeições que fazem diariamente e obteve-se dados importantíssimos que corroboram para futuras pesquisas no âmbito do consumo de alimentos e hábitos alimentares de mulheres inseridas ou não no mercado de trabalho e de sua família.

\section{REFERÊNCIAS}

BRASIL. Constituição (1.988). Constituição da República Federativa do Brasil. Brasília, DF: Senado, 1.988. BRASIL. Código Civil. Organização dos textos, notas remissivas e índices por Yussef Said Cahali. $2^{2}$ ed. São Paulo: RT, 1.999.

BORGES, C. M.; LIMA FILHO, D. O. Hábitos alimentares dos estudantes universitários: um estudo qualitativo. In: SEMINÁRIOS DE ADMINISTRAÇÃO, 7., 2004, São Paulo. Anais..., São Paulo, FEA/USP, 2004.

DECLARAÇÃO UNIVERSAL DOS DIREITOS HUMANOS. Disponível em: $<$ http://www.direitoshumanos.usp.br/index.php/Declara\%C3\%A7\%C3\%A3oUniversal-dos-Direitos-Humanos/declaracao-universal-dos-direitos-humanos.html >.Acesso em: 15 Out. 2015.

GARCIA, R. W. D. Práticas e comportamento alimentar no meio urbano: um estudo no centro da cidade de São Paulo. Cadernos de Saúde Pública, Rio de Janeiro, v.13, n.3, p. 455-467, jul./set. 1997. 
INSTITUTO BRASILEIRO DE GEOGRAFIA E ESTATÍSTICA (IBGE). Cidades@. Campo Grande MS: IBGE, 2011. Disponível em: <http:// www.ibge.gov.br/cidadesat/topwindow.htm?1>. Acesso em: 15 Out. 2015.

LAMBERT, J. L. et al As principais evoluções dos comportamentos alimentares: o caso da França. Revista de Nutrição, Campinas, v.18, n. 5, p. 577-591, out. 2005.

LAMBERT, J.L.; BATALHA, M.O.; SPROESSER, R.L.; SILVA, A.L. da; LUCCHESE, T. As principais evoluções dos comportamentos alimentares: o caso da França. Revista de 45 Nutrição, Campinas, v. 18, n. 5, p. 577-591, 2005.

LELIS, C.T.; TEIXEIRA, C.M.D.; SILVA, N.M. • A inserção feminina no mercado de trabalho e suas implicações para os hábitos alimentares da mulher e de sua família, 2012.

LIMA FILHO, D.O. Valor percebido e o comportamento do consumidor de supermercado: um estudo exploratório em uma média cidade brasileira. Tese (Doutorado em Administração). São Paulo, Fundação Getúlio Vargas, 1999.

MARINHO, M. C. S.; HAMANN E. M.; LIMA, A. C. DA C. F. Práticas e mudanças no comportamento alimentar na população de Brasília, Distrito Federal, Brasil. Revista Brasileira de Saúde Materna e Infantil, v.7, n.3, Recife, 2007.

MINISTÉRIO DO TRABALHO E EMPREGO Disponível em: $<$ http://bi.mte.gov.br/bgcaged/caged_isper/index.php>.Acesso em: 15 Out. 2015.

RODRIGUES, F. S.; SABES, J. J. S. A percepção do consumidor de alimentos "fora de casa": um estudo multicaso na cidade de Campo Grande/MS. Caderno de Administração, Bauru, v. 14, n.2, p. 37-45, 2006.

REVISTA ELETRONICA EDUCAR PARA CRESCER. Disponível em: $<$ http://educarparacrescer.abril.com.br/politica-publica/revolucao-escola475912.shtml\#>. Acesso em: 15 Out. 2015. 
SCHLINDWEIN, M. M. Influência do custo de oportunidade do tempo da mulher sobre o padrão de consumo alimentar das famílias brasileiras. 2006. 119 p. Tese (Doutorado em Ciências) - Escola Superior de Agricultura Luiz de Queiroz, Universidade de São Paulo, Piracicaba, 2006.

SCHLINDWEIN, M. M.; KASSOUF, A. L. Influência do custo de oportunidade do tempo da Mulher sobre o padrão de consumo alimentar no Brasil. Pesquisa e Planejamento econômico, Rio de Janeiro, v.37, n.3, p. 489-520, dez. 2007.

SILIPRANDI, E. Políticas de segurança alimentar e relações de gênero. In: FARIA, N; NOBRE, M. (Orgs.). A produção do Viver. São Paulo, 2004.

SOARES, Sergei; IZAKI, Rejane Sayuri, A PARTICIPAÇÃO FEMININA NO MERCADO DE TRABALHO, 2002 , ISSN 1415-4765.

Enviado: Abril, 2019.

Aprovado: Julho, 2019. 